\title{
Relationship between clinical features of tricyclic antidepressant poisoning and plasma concentrations in children
}

\author{
P. CROME AND R. A. BRAITHWAITE \\ From the Poisons Unit, Guy's Hospital, London
}

SUMmARY Clinical features and drug plasma concentrations were studied in 13 children admitted to hospital with tricyclic antidepressant poisoning. Patients with plasma concentrations below $500 \mu \mathrm{g} / 1$ had anticholinergic signs and increased reflexes but did not have convulsions or cardiac arrhythmias. Four patients with plasma concentrations above $1000 \mu \mathrm{g} / 1$ suffered convulsions, cardiac arrhythmias, or prolonged coma. The diagnosis of poisoning in 2 of these cases was made only by toxicological analysis. Quantitative estimation of tricyclic antidepressants is useful in atypical or severe poisoning both to reach the diagnosis and to give an idea of the likely duration of symptoms.

Accidental poisoning with tricyclic antidepressants has become an increasingly common reason for children to be admitted to hospital (British Medical Journal, 1974; Wynne and Hull, 1977). While most children ingest small quantities and show only minor symptoms of poisoning, serious manifestations of toxicity-such as coma, convulsions, and cardiac arrhythmias-are seen in a number of cases particularly when the dose ingested is $>20 \mathrm{mg} / \mathrm{kg}$ (Brown et al., 1971; Goel and Shanks, 1974).

Noble and Mathew (1969), in a review of the clinical features of tricyclic antidepressant poisoning in adults, reported that neither active drug nor metabolite was detected in the plasma of any of their patients. They therefore concluded that analysis of plasma concentration was of no practical value although quantitative confirmation may be required - e.g. suspected nonaccidental child poisoning (Rogers et al., 1976). Using more refined analytical techniques, recent studies have shown that, in adults, plasma concentrations of tricyclic antidepressants correlate well with the severity of symptoms (Braithwaite, 1977; Petit et al., 1977). We have investigated the value of plasma drug estimation in the diagnosis and management of tricyclic antidepressant poisoning in children.

\section{Patients and methods}

The study was retrospective and covers 1971-77. Received 1 February 1978
All patients under 14 in whom tricyclic antidepressant concentrations were measured and for whom further information was available have been included. Blood samples were sent either directly for tricyclic antidepressant estimation, or were measured after qualitative detection of these drugs as an emergency toxicological investigation. Plasma tricyclic concentrations were estimated using gasliquid chromatography (Braithwaite and Widdop, 1971; Dawling and Braithwaite, 1978).

\section{Case histories}

The clinical features of the 13 patients in this study are summarised in Table 1. More detailed histories of 3 of them are reported below.

Case 2. This 11-year-old girl was transferred to a neurological centre with suspected brain tumour. In the 2 weeks before admission she had been unwell with headaches, vomiting, and dizziness. Two days before admission she had been found unconscious but recovered quickly. On the day of admission she was found unconscious at home and appeared to have stopped breathing. On arrival at hospital she was unconscious with minimal response to painful stimuli, the pulse was 108 and blood pressure $110 / 60 \mathrm{mmHg}$. Both optic discs were blurred, there was generalised hyporeflexia, and plantar responses were extensor. Investigations including lumbar puncture and a CAT scan were normal. Drug 


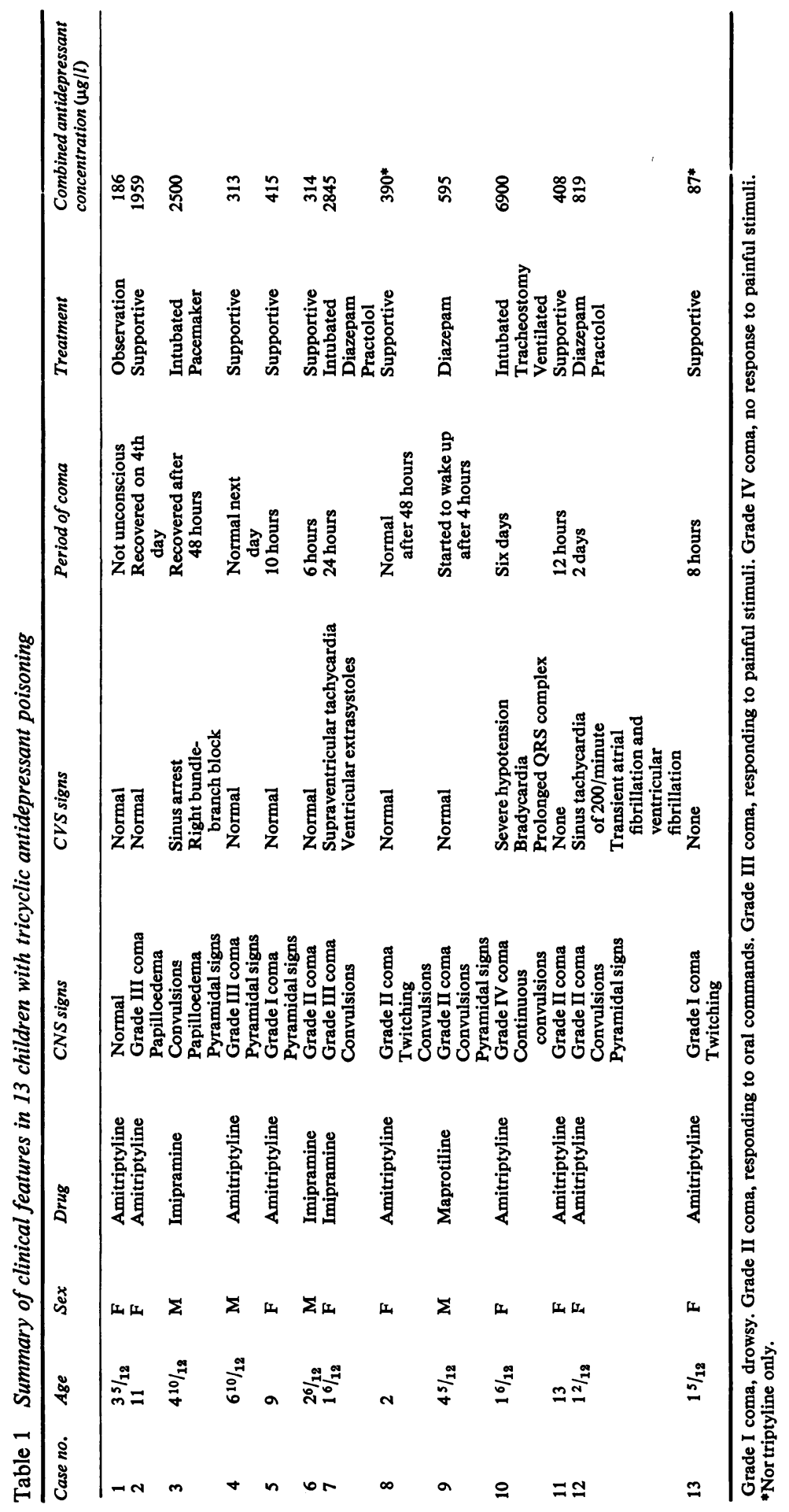


overdose was then suspected and urine screening showed the presence of paracetamol, salicylate, phenothiazines, benzodiazepines, trichloro-compounds, and tricyclic antidepressants. The plasma amitriptyline was $1031 \mu \mathrm{g} / \mathrm{l}$ and the nortriptyline $928 \mu \mathrm{g} / 1$. 24 hours later she started to recover consciousness and had completely recovered by the 4th day after admission. It was thought that she had taken the overdose as a result of depression brought on by viraemia.

Case 3. This 5-year-old boy suffered convulsions on the day after his first diphtheria vaccination. After intravenous diazepam given at his local hospital his pulse became feeble and respiration depressed. $\mathrm{He}$ was intubated and given cardiac massage. Fundoscopy showed papilloedema, encephalitis was suspected and he was transferred to a neurological centre. There he was found to respond to painful stimuli, tendon reflexes were brisk, and plantar response was extensor. His pupils were dilated and nonreacting. ECG showed sinus arrest and right bundle-branch block and a transvenous pacemaker was inserted. The child had been prescribed imipramine for enuresis but his mother denied the possibility of overdose. The combined plasma imipramine and desipramine concentrations were $2500 \mu \mathrm{g} / \mathrm{l}$. He did not become fully conscious until 2 days later. Nonaccidental poisoning was suspected.

Case 9. This $4 \frac{1}{2}$-year-old boy was admitted with a history of six grand mal convulsions during a onehour period. He had also been drowsy for 5 hours but his mother at first denied the possibility of drug ingestion. On examination he was unconscious but responded to painful stimuli. Reflexes were brisk and plantars extensor. After admission he had 3 more convulsions. Four hours after admission he started to wake up, but required diazepam to control violent behaviour. Two hours later the boy's mother telephoned the hospital to say that 7 tablets of maprotiline hydrochloride were missing. A blood sample taken on admission was subsequently shown to have a plasma maprotiline concentration of $595 \mu \mathrm{g} / 1$.

\section{Clinical features}

Most patients in this series suffered symptoms typical of tricyclic antidepressant poisoning (Goel and Shanks, 1974), although two (Cases 2 and 3) had papilloedema which had not previously been described. Case 2, despite having high plasma drug concentrations, had no abnormal cardiac or anticholinergic signs. It is possible that these features were masked by the presence of the other drugs she had taken in overdose although the plasma concentrations of these other drugs were low. Case 9 presented with status epilepticus without any cardiac abnormalities. On admission his mother denied the possibility of drug overdose and had she not subsequently discovered that some tablets were missing the child might have been labelled epileptic.

\section{Severity of symptoms and plasma concentrations}

The severity of poisoning shown by the patients in this series may be divided into three groups (Table 2). Plasma concentration increases with increasing severity of poisoning.

\section{Discussion}

Our results suggest that there is a relationship between plasma concentrations of tricyclic antidepressants and the clinical features in overdose.

Table 2 Severity of poisoning and plasma concentrations

\begin{tabular}{|c|c|c|c|c|}
\hline \multirow{2}{*}{ Severity of poisoning } & \multirow{2}{*}{ Case no. } & \multirow{2}{*}{ Symptoms } & \multicolumn{2}{|c|}{ Plasma concentrations* $(\mu \mathrm{g} / l)$} \\
\hline & & & Mean & Range \\
\hline Mild & $\begin{array}{r}1 \\
4 \\
5 \\
6 \\
11 \\
13\end{array}$ & $\begin{array}{l}\text { Anticholinergic signs } \\
\text { Pyramidal signs }\end{array}$ & 327 & $87-415$ \\
\hline Moderate & $\begin{array}{l}8 \\
9\end{array}$ & As mild poisoning plus convulsions & 595 & 595 \\
\hline Severe & $\begin{array}{r}2 \\
3 \\
7 \\
10 \\
12\end{array}$ & $\begin{array}{l}\text { As moderate poisoning plus } \\
\text { cardiac arrhythmias and prolonged coma }\end{array}$ & 3005 & $819-6900$ \\
\hline
\end{tabular}

*Patients 8 and 11 excluded because only the active metabolite was estimated. 
There are no other studies in children with which to compare our results and very few in adults. Petit et al. (1977) studied 40 patients with tricyclic antidepressant poisoning and found that patients with plasma drug concentrations $>1000 \mu \mathrm{g} / \mathrm{l} \mathrm{had}$ higher incidences of artificial respiration, coma, convulsions, cardiac arrest, tachycardia, delayed intraventricular conduction, and cardiac arrhythmias than those with plasma concentrations $<1000$ $\mu \mathrm{g} / \mathrm{l}$, in agreement with the findings of Braithwaite (1977). Hallstrom and Gifford (1976) however, found no relationship between plasma concentrations and clinical features but only one of their patients had severe poisoning. Fournier (1973) reported that there was no relationship between plasma concentrations and the QRS interval but that drug estimation was of value as it gave an idea of the duration of the patient's illness.

It is generally impracticable and unnecessary to measure drug concentrations as most patients are only mildly affected and the diagnosis is known. Plasma estimation is of value in atypical or severe poisoning (especially if the patient is receiving the drug therapeutically) both to make the diagnosis and to give some idea of the likely duration of symptoms.

We thank Drs R. Goulding and G. N. Volans for help and those physicians who supplied follow-up information about their patients.

\section{References}

Braithwaite, R. A. (1977). Tricyclic antidepressant poisoning-clinical effects and plasma levels. In Clinical
Toxicology. Proceedings of the European Society of Toxicology Congress 1977, volume eighteen, pp. 231-233. Edited by W. A. M. Duncan and B. J. Leonard. Excerpta Medica International Congress Series No. 417. Excerpta Medica: Amsterdam.

Braithwaite, R. A., and Widdop, B. (1971). A specific gas chromatographic method for the measurement of 'steadystate' plasma levels of amitriptyline and nortriptyline in patients. Clinica chimica acta, 35, 461-472.

British Medical Journal (1974). Editorial: Irresponsible poisoning. British Medical Journal, 1, 296-297.

Brown, T. C. K., Dwyer, M. E., and Stocks, J. G. (1971). Antidepressant overdosage in children-a new menace. Medical Journal of Australia, 2, 848-851.

Dawling, S., and Braithwaite, R. A. (1978). A simplified method for monitoring tricyclic antidepressant therapy using GLC with nitrogen detection. Journal of Chromatography, 148, in press.

Fournier, E. (1973). Intoxications par les antidépresseurs tricycliques. Thérapie, 28, 307-320.

Goel, K. M., and Shanks, R. A. (1974). Amitriptyline and imipramine poisoning in children. British Medical Journal, 1, 261-263.

Hallstrom, C., and Gifford, L. (1976). Antidepressant blood levels in acute overdose. Postgraduate Medical Journal, 52, 687-688.

Noble, J., and Mathew, H. (1969). Acute poisoning by tricyclic antidepressants: clinical features and management of 100 patients. Clinical Toxicology, 2, 403-421.

Petit, J. M., Spiker, D. G., Ruwitch, J. F., Ziegler, V. E. Weiss, A. N., and Biggs, J. T. (1977). Tricylic antidepressant plasma levels and adverse effects after overdose. Clinical Pharmacology and Therapeutics, 21, 47-51.

Rogers, D., Tripp, J., Bentovim, A., Robinson, A., Berry, D., and Goulding, R. (1976). Non-accidental poisoning: an extended syndrome of child abuse. British Medical Journal, 1, 793-796.

Wynne, J., and Hull, D. (1977). Why are children admitted to hospital? British Medical Journal, 2, 1140-1142.

Correspondence to Dr P. Crome, Poisons Unit, Guy's Hospital, London SE1 9RT. 